\title{
Academic Persistence Among Native American College Students
}

Aaron P. Jackson

Brigham Young University - Utah, aaron_jackson@byu.edu

Steven A. Smith

steve_smith@byu.edu

Curtis L. Hill

Follow this and additional works at: https://scholarsarchive.byu.edu/facpub

Part of the Counseling Psychology Commons

\section{Original Publication Citation}

Jackson, A. P. \& Smith, S. A. \& Hill, C. L.."Academic Persistence Among Native American College Students." Journal of College Student Development 44.4 (2003): 548-565. Project MUSE. Web. 12 May. 2016. .

\section{BYU ScholarsArchive Citation}

Jackson, Aaron P.; Smith, Steven A.; and Hill, Curtis L., "Academic Persistence Among Native American College Students" (2003). Faculty Publications. 1591.

https://scholarsarchive.byu.edu/facpub/1591

This Peer-Reviewed Article is brought to you for free and open access by BYU ScholarsArchive. It has been accepted for inclusion in Faculty Publications by an authorized administrator of BYU ScholarsArchive. For more information, please contact ellen_amatangelo@byu.edu. 


\section{PROJECT MUSE*}

\section{Academic Persistence Among Native American College}

Atudp. Jackson, Steven A. Smith, Curtis L. Hill

Journal of College Student Development, Volume 44, Number 4, July/August 2003, pp. 548-565 (Article)

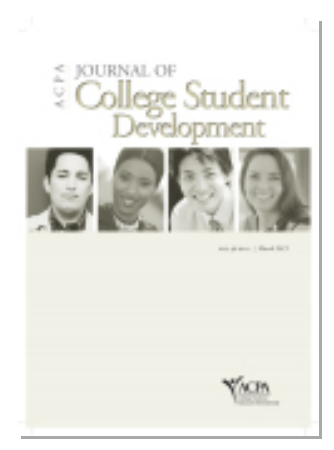

Published by Johns Hopkins University Press

DOI: 10.1353/csd.2003.0039

$\Rightarrow$ For additional information about this article http://muse.jhu.edu/journals/csd/summary/v044/44.4jackson.html 


\title{
Academic Persistence Among Native American College Students
}

\author{
Aaron P. Jackson Steven A. Smith Curtis L. Hill
}

Qualitative interviews with 15 successful Native American college students who grew up on reservations identified the following themes related to their persistence in college: (a) family support, (b) structured social support, (c) faculty/staff warmth, (d) exposure to college and vocations, (e) developing independence and assertiveness, (f) reliance on spiritual resources, ( $g$ ) dealing with racism, (h) nonlinear path, and (i) paradoxical cultural pressure. The results indicated a need for stable mentoring relationships and programmatic support.

The academic difficulties and nonpersistence of Native Americans in college are well documented (Steward, 1993; U.S. Department of Education, 1998). Despite evidence of academic ability, postsecondary dropout rates are higher for Native Americans than for any other minority (Reddy, 1993). Native Americans are also underrepresented in graduate programs (LaFromboise \& Low, 1989; U.S. Department of Education, 1998). Accordingly, Native Americans consistently have lower educational attainment than other ethnic minorities (Lin, LaCounte, \& Eder, 1988; U.S. Department of Education). This is particularly unfortunate given evidence that indicates that once Native American students graduate from college they have initial salaries comparable to the rest of the population and complete graduate and professional programs at a rate comparable to the rest of the population (U.S. Department of Education).

The high rates of Native American nonpersistence in college and their lower representation in the general college student population are puzzling, especially considering that they earn SAT and ACT scores comparable to other ethnic minority groups and have equivalent high school graduation rates (Reddy, 1993; U.S. Department of Education, 1998). Also, despite the fact that Native Americans have recently been admitted to college in such numbers that they are slightly overrepresented in initial enrollments in college, they persist at significantly lower rates than the rest of the population. For example, in NCAA Division I schools the persistence rate for Native American students is about $54 \%$ after the first year. For the general population the persistence rate into the second year is $68 \%$. Likewise, the persistence rate into the third year is $33 \%$ for Native American students and $49 \%$ for the rest of the population. Accordingly, only $36 \%$ of Native American students have graduated within 6 years of initial enrollment. Fifty-six percent of the total population graduates in the same period (U.S. Department of Education). The purpose of this study was to explore successful Native American college students' experiences to better understand the barriers to postsecondary success and the means to overcoming those barriers.

Aaron P. Jackson is Assistant Professor of Counseling Psychology and Special Education at Brigham Young University. Steven A. Smith is Associate Clinical Professor in the Counseling and Career Center at Brigham Young University. Curtis L. Hill is a counselor in the Wellness Center at Southern Utah University. 
Several authors have attempted to explain the puzzle of nonpersistence among Native American students. Their conclusions can be divided into three categories: (a) sociocultural factors, (b) academic factors, and (c) personal factors.

\section{Sociocultural Factors}

Lin et al. (1988) suggested that Native American college students feel isolated due to their perceptions that the "White campus is hostile towards them" (p. 13). Benjamin, Chambers, and Reiterman (1993) also concluded that lack of academic persistence was due to colleges' failure to accommodate Native American culture. Other studies (Lamborn et al., 1997; Lin, 1990; Ward, 1998) have suggested that a clearer sense of ethnic identity may lead to better academic performance. Willeto (1999) also found that family influences such as parental education, students' identification with their mothers, and family adherence to traditional cultural practices contributed to commitment to academic commitment and achievement. Rindone's (1988) quantitative study of over 100 Navajos who had successfully completed at least a bachelor's degree also suggested that family encouragement and family adherence to traditional practices were key contributing factors to successful students' experiences. Brown and Kurpius' (1997) data indicated that Native Americans will have greater persistence in college if they have more positive interactions with faculty members (cf. Hornett, 1989). Brown and Kurpius further suggested that finding mentors and creating support groups would be of great benefit (cf. Braithewaite, 1997; Hoover \& Jacobs, 1992).

\section{Academic Factors}

Brown and Kurpius (1997) found significant relationships between persistence and better high school preparation. They suggested that Native American students receive more training in study skills and college preparation. Hoover and Jacobs (1992) argued that Native Americans do not receive adequate preparation from their high school counselors regarding planning for postsecondary education and careers. They proposed that this leaves these students ill prepared to successfully navigate postsecondary education. Other studies have suggested that better preparation with study skills and career development will lead to greater persistence (Sakiestewa, 1996; West, 1988)

\section{Personal Factors}

Brown and Kurpius' (1997) showed a significant relationship between Native American students' academic aspirations and persistence in college. Kerbo's (1981) data suggest that Native American students' confidence in their ability to succeed is of greatest importance. McInerney and Swisher (1995) noted that perceptions of confidence and competence were key aspects of $\mathrm{Na}$ tive Americans' motivation for academic achievement. Rindone's (1988) finding that achievement motivation was a significant factor in postsecondary success supports this focus on personal motivation variables. A number of demographic variables have also been implicated in Native Americans' persistence challenges. Lower levels of financial support from both family and institutional sources, as well as much higher rates of other related risk factors such as, delayed enrollment, part-time attendance, financial independence, working full-time, being a single parent, and being a GED recipient (U.S. Department of Education, 1998) have been identified as personal variables that impact persistence. 


\section{Participants' Perspectives}

Although each of the aforementioned variables areas may affect Native Americans' persistence in college, these variables were derived from preconceived notions regarding what contributes to academic success in college. Quantitative studies typically rely on theoretical assumptions that are spelled out in the research hypotheses and inherent in the survey items and the researchers' choice of sampled data. In their discussion of the limitations of the quantitative studies of Native American students' postsecondary experience, the authors of American Indians and Alaska Natives in Postsecondary Education (U.S. Department of Education, 1998) concluded that "qualitative studies should be considered to complement and enhance the quantitative data" (p. xxxvii). In keeping with this recommendation, we implemented a qualitative approach for the following reasons.

1. Current understanding of postsecondary persistence among Native Americans has come from models of academic nonpersistence and career difficulty, which are based in European American culture. Native American culture is distinctly different from European American culture, and tribal cultures are distinct from one another. Unique models of educational development need to be developed for Native American populations (McCormick \& Amundson, 1997).

2. Qualitative approaches allow the researcher to discover the unique cultural perspectives participants may have regarding their postsecondary experience (Herring, 1999; Lee, Mitchell, \& Sablynski, 1999).

Qualitative methods offer a means to identify key factors from the participants' point of view. Some researchers have used qualitative methods to assess Native Americans' postsecondary experiences. Steward (1993) conducted intensive case studies in an attempt to collect data from the Native American students' point of view. His data tended to support the variables suggested by previous authors (i.e., acculturation, preparation, and personal variables were important to these students). However, much of his information was based on data collected through standardized instruments, which are based on existing theories and paradigms typical of European American culture. Our study worked to extend the qualitative investigation of academically successful Native American college students by limiting the imposition of assumptions and allowing participants to provide deep descriptions of their postsecondary experience and their perceptions of key aspects of their success.

Though we attempted to limit our assumptions in conducting the interviews and analyzing the data in this study, we acknowledge several implicit assumptions. First, we assumed that higher education is valuable and that there are factors that facilitate or detract people in the process of higher education. Second, we assumed that these factors were cultural, social, institutional, and familial. These assumptions are evident in the interview guidelines and sample questions (see Appendix). Finally, we assumed that we could gain insights into Native American students' college experience by conducting empathic interviews and faithfully analyzing the transcripts of those interviews (Kvale, 1996). Given these assumptions, our purpose in this study was to articulate academically successful Native American college students' perceptions of the factors that facilitated and detracted from 
their efforts to graduate from college.

\section{METHOD}

\section{Participants}

The participants were 15 Native American college seniors, 8 men and 7 women. Participants were identified and recruited through multicultural student support offices at 5 four-year colleges in the Southwestern United States. Each participant was paid \$20. Flyers inviting participation were placed in the multicultural offices and emails inviting participation were distributed to leaders of Native American student groups. If a list of Native American students was available, individual students were randomly contacted and invited to participate. At most of the schools the students meeting the criteria for inclusion in the study were so rare that the multicultural office personnel knew them personally. The criteria for inclusion in the study were that the students (a) had lived on a reservation for the majority of their school years - including at least 2 of the last 4 years prior to beginning college, (b) had parents who both identified themselves as Native American, (c) were seniors in good academic standing, and (d) had been enrolled in college no longer than 7 years. Our rationale for each of these criteria were (a) students who had grown up on the reservation were likely to experience the most extreme crosscultural transitions, (b) students whose parents both identified themselves as Native American were likely to have a primarily Native American identity, (c) seniors in good academic standing were highly likely to become college graduates but were more accessible than students who had already graduated, and (d) students who had been enrolled fewer than 7 years had participated as full-time students for most of their college experience. Students participating in the study represented four different tribesNavajo/Dine', Paiute, Pueblo, and Utefrom three different states. The participants' age range was 20 to 32 years, with a mean of 25.6 years. The GPAs of the students ranged from 2.20 to 3.68 with a mean GPA of 2.90. The colleges were selected to represent a range of sizes and emphases on research versus teaching. All of the colleges had a typical ethnic mix, with approximately $75 \%$ to $90 \%$ European American students.

\section{Procedure}

The authors, each of whom had training and experience in qualitative methods, conducted the interviews. Each author conducted at least three interviews. All of the interviews were done one-on-one. A list of interview topics with guidelines and sample questions was used to help interviewers avoid leading questions and to maximize the depth and breadth of interviewee responses (Patton, 1990; see Appendix). The interviews were conducted in person and ranged from 45 to 75 minutes in length. Participants also completed a brief demographic questionnaire and an informed consent form. Each interview was recorded, transcribed, and then interpreted by the researchers using a synthesis of interpretive qualitative methods (Kvale, 1987, 1996; Packer, 1985; Polkinghorne, 1984, 1991).

The philosophical foundation for the method of the study was based on a relational ontology (Jackson, Slife, \& Williams, 2003; Schwandt, 2000). That is, our fundamental assumption was that relationships are primary and necessary to understanding human experiences. Accordingly, our epistemological foundation for our method was hermeneutic and dialectic (Denzin \& Lincoln, 2000). A key tenet of this epistemology 
is that "understanding is something that is produced in [that] dialogue, not something reproduced by an interpreter through an analysis" (Schwandt, 2000, p. 195). In keeping with this philosophy, we incorporated Kvale's (1996) approach to interviewing. This approach included the following aspects (adapted from Kvale, 1996, pp. 30-31):

1. Attention to the everyday "life world" of the participants.

2. Efforts to understand the meaning of the themes in the dialogue.

3. Dialogue aimed at qualitative rather than quantitative knowledge.

4. Encouragement of in-depth descriptions of the participants' experience.

5. Encouragement of descriptions of specific experiences.

6. A deliberate openness to novel and unexpected perspectives.

7. Focus on the phenomena of interest without using restrictive questions.

8. Acknowledgement of possible ambiguities and contradictions in the dialogue.

9. Awareness of new insights that may come to interviewer and participant in the interview.

10. Knowledge that each interviewer brings varying degrees of sensitivity to different aspects of the participants' experiences and perspectives.

\section{Analysis}

The interpretation of the transcribed interviews used the same philosophical and theoretical assumptions as were used in conducting the interviews. The postinterview interpretive process is described below:

1. Conduct an unfocused overview of the text. This is an attempt to study the text with as few presuppositions as possible and to approximate the meanings articulated in the dialogue with the participants (Jackson \& Patton, 1992; Kvale, 1996).

2. Make tentative interpretations through successive readings of the material. This process, sometimes referred to as the hermeneutic circle, has been described as a spiral or reflexive process in which the investigators seek to uncover progressively deeper levels of meaning in the text (Hoshmand, 1989; Kvale, 1996; Polkinghorne, 1984).

3. Find language that accurately conveys the findings. Once valid interpretations have been made (Kvale, 1987, 1996), the research team works to effectively communicate the findings. Precise description of the meaningful themes is the goal product.

Two of the researchers participated in the initial analysis, which was conducted as follows. First, each of the researchers conducted several successive reviews of the transcripts, using the process described above, to identify an initial set of themes. Themes that continued to be supported in successive readings of the transcripts were retained. Themes that did not have broad support in successive readings of the transcripts were removed. Once the two investigators had concluded this initial independent analysis, they brought their findings together for comparison and additional analysis. Themes that were found by both researchers were retained. The remaining suggested themes were evaluated by both researchers, using the procedure described above, to determine whether or not there was sufficient evidence to warrant inclusion of the theme. Themes were retained only if the researchers 
were able to come to consensus about their validity. To further assess the validity of the themes, the third author, who did not participate in the analysis, presented the themes to three of the participants and asked them to comment on the verity of the them vis-à-vis their own experience. These participants concurred that the themes were representative of their experience. Participant responses to the initial findings were incorporated as the research team refined the themes. As an additional validity check, the initial findings were also presented to a group of 12 Native Americans who were leaders in education funding programs for Native Americans. These individuals were also in agreement with the identified themes and indicated that they were consistent with their own experiences and the experiences of many Native American college students with whom they were familiar.

\section{RESULTS}

Our analysis provided results at two levels of depth. The first level included the rather obvious "surface" themes that developed in the interviews and analysis. These themes were typically straightforward and consistent with previous research findings. The second level of depth included findings that were more personal and more complex, contradictory, or multifaceted. These themes added to the existing research.

\section{Surface Themes}

Family support. Students talked about the strong encouragement and support they received from one or both of their parents or a first- or second-degree relative, such as a grandparent, aunt, or uncle. In many cases the encouragement was almost an imperative to be academically successful. One student described her experience after her father died:
[Going to college] was embedded in me from the beginning. Yeah, we had to go. It was something we couldn't get out of. ... I don't know if I would have ever gone to college if my dad didn't die, but I think we still would have, because it would have been expected by him.

Another participant reported the sacrifices her parents were willing to make to help her be successful:

There were times I wanted to give up. "Why am I doing this? I should just go and get a job." But my mom said, "Just keep at it. If money's a problem we'll sell the cows." So we sold a lot of cows over the past several years.

These results were consistent with research by Rindone (1988) and Willeto, (1999) which found that family encouragement was positively related to commitment to academic achievement.

Structured social support. Students talked about the positive effects of Native American clubs, multicultural offices and other groups organized to provide social support to Native American students. They saw their association with such groups as a critical aspect of their success despite the fact that many of them were initially reluctant to be involved in these groups. Some students went so far as to recommend that involvement in such groups be made mandatory. One student described her experience with such a student group:

Being a minority in [the city] was really hard because I didn't have anybody to talk to and I had nothing in common with anybody. And then [after joining the student group] it was nice to see brown faces, because there's somebody you can identify with or talk to. And I think most of us have the same struggles of dealing with homesickness and 
having to miss different ceremonies throughout the year and missing traditional foods.

Another student reported her contact with career role models through a club:

I was part of a club back then. They had conferences and I think that helped me a lot - to see Native American people who were entrepreneurs. Like this lady, she was an engineer, this computer person. To see her being an engineer kind of motivated me. I guess she was a good example, a role model. ... And there were other Native Americans who own businesses, like web-designing or something like that. It seemed hard to me, but now that I'm graduating-I'm afraid to go out in the world. But I want to-I want to be like the lady who works for that laboratory.

These results were supportive of research by Brown and Kurpius (1997) and Hoover and Jacobs (1993), which suggested that creating support groups would improve retention of Native American students.

Faculty/staff warmth. Students talked about the positive experience of being greeted and contacted warmly by faculty and staff. Some students contrasted their experience at one school with that at another school or their experience in one department versus another department. The determining factor in these contrasting descriptions was the degree to which the faculty and staff personally engaged the student. The students reported that they perceived that these individuals actually cared about them. This perception of care from faculty/staff gave them confidence that they had (a) a place to go to ask questions about the college or university, and (b) an important personal connection to the college or university. One student contrasted her experiences with faculty members at two different colleges:
Teachers didn't know me at [my previous college]. I mean like they didn't know what class you were in, you know? It was like that. Here they know me; [these three professors], they all know me. [These two other professors], they all know me.

A second student reported his experience as follows:

I think once I realized that professors are so willing to help you, you're much more willing to go in and say, "I need help with this." I think just establishing your relationship with your professor and, I mean, my advisor, I've had a few classes from him-it's always, he's always kept an open door with me. I can go in and ask him for help. And that's been nice - establishing a relationship with my advisor and my professors.

These findings supported previous research that has pointed to the importance of student-faculty relationships in the experience of Native American college students (Brown \& Kurpius, 1997; Hornett, 1989).

Exposure to college experiences and possible vocations. Students indicated some previous positive experience with the college environment. In many cases these were structured experiences such as those available through Upward Bound and similar programs. Students also reported being exposed to the environment while living with parents who were attending college or through other close relatives who were attending college. One student talked about his experience with the Upward Bound program:

I was in the Upward Bound program in high school. So, during the summer I would take college courses. We got exposed to the whole college life, you 
know, staying in the dorms, and having responsibilities, waking up early in the morning, and doing homework. I guess that really prepared me and I'm glad I had that experience, because if I went to college not knowing those things, I probably would have struggled a little bit more.

Likewise, students reported benefiting from exposure to people from circumstances similar to their own, who were in vocations that required a college education. They indicated that these experiences provided them with a familiarity that eased their transition to the college environment and increased their confidence that they could successfully navigate it. One student reported, "That's probably the only thing that made me go into computers, is my senior year; I took a tour of [business]. And there was a little section . . . with the computersand I said, "This would be so cool."'

Developed independence and assertiveness. The participants reported that they experienced an existential shift toward being more independent and outgoing. They reported becoming more willing to ask for help and more comfortable speaking in social situations. For some students, this happened when they were young, for others it happened as part of their adaptation to college. This was illustrated in their descriptions of how they tried to stay connected to their home and community without feeling bound by it. It was also illustrated in descriptions of how they adapted to the dominant culture. One student described the shift she experienced in college:

I was part of the [Native American] club [at a previous college], but I never ran for things. And here I ran for it [club office] and I got it. ... I started participating and was . . . usually, I'd be just quiet and to myself and not say much.
I would sit there, and they'd start having this panel discussion, when they pick students to ask questions about their culture and whatnot and then I was like, "Cool." And then I started speaking out. I thought, you know, "I can speak out!" I felt my shyness kind of went away.

One student, who reported coming from particularly difficult circumstances, described his experience of gaining independence:

I had reading problems. This one time, I can't remember what grade it was in, but when I was going to school, they put me in [a] special [education] class for reading. Then I was determined to get out of that class so bad. So what I started doing was I started reading my books like I was supposed to-started reading them, because I didn't want to be in there.

Previous research has identified confidence and several related self-perception and motivation variables as possible predictors of academic persistence (Brown \& Kurpius, 1997; Kerbo, 1981; McInerney \& Swisher, 1995; Rindone, 1988). Our findings offer general support for the idea that confidence and self-efficacy, based in experiences that lead to more independent and assertive attitudes, are related to academic persistence.

Reliance on spiritual resources. Though the participants' level of traditional spirituality varied considerably, for some students it was a significant source of strength in completing their academic work. One participant described a critical turning point in her education:

I think something touched me. I went and had a ceremony done. ... Ever since then I haven't wanted to drink or smoke. I started being serious about school. . . . Since I've had my ceremony I've really gotten in contact with my 
traditional prayers, and the things my people, my ancestors . . . they've given us like sage, cedar, sweet grass, and tobacco. I've learned how to use them, instead of using alcohol to cope.

Another participant reported:

I would use my traditions. I would get prayers done. I would get ceremonies done for my education. That would help me. .. . [Over] a semester I would have a prayer done at least once a month. That's what helped me a lot.

Though relatively little research has focused on the use of spiritual resources, Willeto (1999) found that traditional cultural practices may contribute to persistence. Our findings suggest that the spiritual aspect of traditional cultural practices may provide support for Native American college students.

\section{Deep Themes}

These themes were identified only after we were more deeply involved in the interviews and subsequent analysis. The interview dialogue from which these themes emerged typically occurred after the researchers had established some level of trust with the participants. Likewise, these findings became clear only after considerable analysis and were somewhat surprising given their departure from the existing literature.

Dealing with racism. Though racism is a common topic in both scholarly and everyday dialogues, we included it as a deep theme because of the poignant quality it had in the interviews and because of our own surprise at its prevalence and its degree. Though our surprise may have been due to our naiveté, we imagine it is a typical response - particularly for European Americans working at universities and colleges. We suppose that many members of the dominant culture like to believe that chronic and blatant racism is waning on university campuses (cf. Sydell \& Nelson, 2000). Our interviews suggested just the opposite for our participants. Students reported experiencing both passive and active racism. The passive racism was experienced as either being ignored or being singled out as a representative of their race or culture. This led to feelings of isolation or social pressure. Students saw this as an inherent aspect of their experience that they had to manage. One student described his experience in finding a lab partner:

Like when you get in group studies, or like when you're doing experiments, you're supposed to have partners or groups. No one actually came up to me and said, like I would say, "Do you want to be part of our group?" or just expressed the willingness - that humble feeling of being very open. Here everyone is just like, "Oh, there's a brown kid ... I don't know." And I had to go out big-time to go break down barriers and say, "Hey, do you need another person? Can I be part of your group?" I had to take that extra effort to be part of a study group. So, it was more of a heavy burden for me.

Another student described her experience dealing with teachers in high school and college:

I think that sometimes I've been a token Indian, I guess, where teachers in high school and a professor or two have let me get away with mediocre work, just because I'm brown and they think that I can't really do anything better.

Many experiences of prejudice were subtle. Although the offenders were apparently doing so only out of ignorance, the students still experienced the added burden 
of dealing with challenges like the one described by another student:

It's kind of hard to deal with somebody who's traditional coming off the reservation, I think, for a White person. Because, I had a hard time in high school, because I was raised not to look directly into somebody's eyes, you know, an older person's eyes. I mean, it's just out of respect - and you never, you don't raise your hand in class, you know, to bring attention to yourself. That was hard, because there were a lot of participation points that I would miss. ... I've had a couple of professors that approached me and said, "I wish you'd speak more in class." That doesn't help anything. That just makes me want to not say anything at all. . . Because it's like I'm the only brown person in a lot of my classes and I'm expected to speak up for all the brown people in the world, and I just don't like that.

Active racism was typically experienced in classes or other discussions about historic or cultural issues. Students reported that they felt marginalized and offended in these interactions. One student described this experience:

In my English class, we were reading an African story about how [Europeans] Christianized them, and the teacher was bringing up Native Americans. And this one guy would make comments about [Native American] religion. And I was like, "Who the hell are you to say stuff?" Sometimes what [people] say is just boldly, straight-out racism. They say things to you or they'll talk about Indians. And sometimes they'll hint. They'll come across subtle, but you still see it. And that just makes [me] mad, and it makes [me] not want to hang out with people, you know what I mean? I think that's the big reason, you know, I don't want to hang out with people who look at me differently.

Another student described a similar experience:

In class . . they try to tell you about Native Americans, teach you about Native Americans, like anthropology or like some of the writing classes. And I remember at [university] it was really deadbeat. They would write some very awful things about Native Americans. And even at [community college] you had to take U.S. history. And they would degrade the Native American people. That was an obstacle. And like I say, some people can stand up and say, "Hey, I don't like that," and, "This is wrong." And some people learn to put their head down and just keep quiet. So, I was kind of like ... I just let it go. I didn't confront any professors. I was offended. I was hurt. You know, there were times in class I would freak out. Those were some things that got in the way because ... you were being attacked by the teacher.

Though racism has received considerable scholarly attention, we found little research that focused specifically on the personal experience of racism and its relationship to persistence among Native Americans. Some research has focused on Native Americans' perceptions of the campus climate as hostile (Lin et al., 1988) or unaccommodating (Benjamin et al., 1993; Sanders, 1987) but little research has focused on Native American students' experiences of racism per se (cf. Huffman, 1991). The question of whether the lack of attention to this issue is itself a form of institutionalized racism will be explored in our discussion of the results.

Nonlinear path. None of the students reported a linear path to academic success. Each of them had attended at least three 
schools in the process of getting their degree, frequently receiving an associate's degree from a two-year college en route to their bachelors degree (cf. U.S. Department of Education, 1998). Students also tended to have breaks from attending college of up to 2 years. Likewise, most of them had periods over the course of their academic career, when they struggled academically. This was true even for students who had accumulated high GPAs and academic honors. Discussion of this nonlinear path typically emerged over the course of the entire interview and was therefore difficult to illustrate in a sample quotation. However, one participant summarized her path as follows:

I went to [Community College 1] that year. I came back [home] for the summer to go to work. I applied to go to [University 1] and I got in. I also got into [University 2]. But then I met my husband and didn't really want to go to leave him behind. I went to [University 1] but I didn't have a dorm. So, I didn't have anywhere to stay. I stayed with my cousin for a while, but she had a new baby and I didn't want to impose on them. I withdrew myself and had everything sent down to [Community College 2]. That's where I started for my second year. And I got my associate's [degree] there. And then I decided to go to [University 3], just so I could be close to where [my husband] was.

A second student described her experiences of going in and out of several schools:

Before I got pregnant, I [moved to a city] between [University 1] and [Community college]. I was kind of taking classes at both of them, not doing well at all. I met my boyfriend, and I got pregnant, and it seemed like things changed. I finished. I did what I did there, and then I moved home to have my baby. I had him, and I waited ... a a year, and then I started school at [University 2]. I did well there for a year. Then I went to [University 3], stayed there a year. And now I'm here at [University 4].

Perhaps more important than the students' respective academic timelines, was their manner of discussing them. We were struck by the matter-of-factness of the descriptions. The participants were not embarrassed or apologetic about their path, as one might expect of European American students. They seemed to have less of a sense that graduating in a timely manner (as defined by the dominant culture) was somehow better than taking longer to graduate. Likewise, the participants seemed comfortable with their decisions to leave college for a time to help with family difficulties or address other personal needs. Our sense is that the nonlinear path and the relative comfort with such paths experienced by our students are reflections of fundamental cultural diversity - in this case a value of cyclic rather than linear progression. It may also be reflective of other differences between cultural values typical of Native Americans and European Americans. For example, many Native American cultures are less competitive than the dominant culture. They may also value the present more than the future (Jackson \& Turner, in press). Though previous research has noted that Native Americans typically take longer to graduate than their peers, it has not discussed what meaning these delays might have for the students themselves.

Paradoxical cultural pressure. Students discussed conflicting pressures to (a) be successful in college and (b) maintain their identity as a member of their reservation community. They said that their family and 
community supported their academic efforts and were proud of their success in college. At the same time, they reported feeling somewhat uncertain about their families' and communities' acceptance of them as a college graduate or as a student or professional in a particular discipline. One student reported his experience of describing what he was studying to members of his family:

And my parents, my family would say, "Oh, that doesn't mean anything to us, we're Native Americans." That's for the other ... White people, in other words. So there was a problem ... you go to school, you're paying all this money to learn something. You're working hard, you're studying, writing papers, doing research, and then you come home and your family says, “That doesn't apply to us. Go take your education someplace else."

Paradoxical influences were also evident among the students' friends. They reported mixed effects of having friends from the reservation attend college with them. They indicated that, although these friends provided comfort and relief from isolation, they also pressured them to engage in activities that inhibited their academic success, such as excessive drinking. Some students reported changing schools to avoid these negative social pressures. Some participants purposely attended different schools than their friends from the reservation did, to avoid what they believed would be their negative influence. One student said, "The main reason I didn't go to [a particular college] was because I knew friends would be there, and I knew a lot of people there." Another student talked about the dilemma at her college:

I think [my friends] have been both positive and negative. I mean, it's kind of hard to study when your friends want to go and watch a movie, you know, or go hang out. I mean it's ... that's been kind of hard. I think that's been the negative part of it ... just saying no to joining them in activities. I think the positive thing is-it's nice having somebody around to talk to, you know, somebody to hang out with and just talk and share stuff.

Although it seems intuitively valuable to have friends from home attend college with you, the participants saw having such friends around as a mixed blessing. They felt that their friends exerted considerable pressure not to be successful in college. Though research has examined the role of alcohol, drugs, and other distractions in reducing persistence, little attention has been paid to the people who present these distractions.

The participants reported feeling some pressure to reconcile the fact that they had left their reservation. Many of them indicated a desire to return to their reservation to help the people there. Others said that they felt they had to cut their connections to the reservation as a means of maintaining their success. This strategy was implemented when the students' connections to home and community were largely negative or painful. One participant, when asked if he currently felt connected to his homeland, responded as follows:

No, not really. I stay away from it because of all the problems they have on the [reservation]. You know, alcoholism. Alcoholism is pretty bad. I got into that after high school in like 11th or 12 th grade. . . . It was a lot easier, I found out, just to move away, to get away from the problems. ... Murder, suicide rate, yeah, it's pretty high. I had two [relatives]; they committed suicide. 
The same participant, when asked later in the interview about his future plans, said, "I might be going back to the [reservation], yeah, to help the community out, but not live on the [reservation]."

Another participant described his relationship with the reservation:

It's harder to relate to people [at school] when you're who you are, you know, because I think it's different. Being on the reservation, I mean, you have your own ... the way you talk, you have an accent, everything's different, you know. Walking around college, you just don't fit. I mean, I don't act the way these people act, you know, I can't act the same, and when you go ... I mean you have friends and stuff, but you leave it all behind. I don't have anyone who acts like me [here at school].

This dilemma was often heightened as students contemplated entering their vocations. One participant summarized this challenge:

I want to work on the reservation, that's what I want. But there really aren't many jobs available for [my field]. They're barely getting there. I saw one advertisement for a [job in my field]. I was like, "Oh my God, they have my ... I hope it's still available when I graduate." But if they don't really have anything, I guess I could say I'll have to move to a big town or city, [where] I've seen a lot of job openings.... But I want to work where I live.

Though students feel considerable pressure to leave the reservation, attend college, and enter a prestigious profession, they feel that if they do those things they will not be able to maintain their identity as a legitimate resident of the reservation and its culture-whether they choose to live on the reservation or not. They fear they will be seen as a sellout for acculturating to the dominant culture's definition of academic and vocational success. One previous study identified a similar theme among Native American students attending a tribal college (Ness, 2001), but relatively little research has attended to this complex issue.

\section{DISCUSSION}

It is difficult for many Native American students to pursue and receive a college degree. Besides the inherent difficulty of racism and struggles faced by students coming from rural environments, students raised on a reservation experience difficulties in acculturation that are unique to them. First, many are first-generation college students. Their families and culture may not easily accommodate the commitment necessary to succeed in college. Family members may not understand why these students must leave home for extended periods of time and be absent from important cultural and family events. Additionally, a commitment to family typically requires a parallel commitment to culture that can conflict with pursuit of a college degree (Jackson \& Smith, 2001; Reddy, 1993). Second, Native Americans raised on a reservation often face the difficulty of leaving a place of spiritual and cultural significance. Making a commitment to leave the reservation to pursue a college degree can be seen as selling out to a different culture and way of life. Additionally, students have no guarantee that the degree they pursue will be valuable if they want to go back to the reservation (cf. Martin, 1991). The very study of some disciplines may be seen as going against the culture. For example, the study of medicine or related fields may be seen as going against some traditional Native American cultures 
or as a violation of cultural mores (Jackson \& Smith, 2001).

However, students in this study found ways to cope with the difficult cultural and societal pressures unique to Native Americans. These students demonstrated resilience in pursuing their degree. They continued to pursue their degree, even after struggling academically, taking long breaks from their studies, feeling discouraged by racism, moving from one college or university to another, or perceiving that they had little support from their college or university. They demonstrated determination to find personal and financial resources to help them in their pursuit of a degree. Students discussed feeling discouraged by the barriers to receiving their degree but found ways to overcome their discouragement and continue with their studies. These students appeared to have an exceptional ability to take advantage of resources that were available to them.

Certainly exposure to college and family support were factors that helped these students to develop the resilience necessary to continue in college. However, there may be other abilities innate to these students that helped them develop the resilience to succeed in college. Several abilities do not appear to be explained by exposure to college and family support. The ability to take advantage of opportunities on campus, the ability to feel part of a culture without being bound by it, the ability to adapt to a different culture, and the ability to effectively deal with racism may be due to personal attributes more than family support. There may also be spiritual or cultural components to these students' strengths that were not fully explicated in this study. Future research should continue to explore and articulate these factors.

\section{Implications}

Based on the results of this study and the related existing literature, we have several observations and recommendations for helping Native American students have positive experiences in college. At the broadest level, our study suggests that Native American tribes and communities need to attend to the contradictory messages that may be implicit in their values. Tribal leaders might articulate more clearly how higher education and identification with the community can be reconciled. We found that this reconciliation does take place at the family level, but addressing the same issues at the community and tribal levels may prove helpful-especially to students who lack strong family support. Another possibility, given the importance of traditional spiritual resources to some college students, would be to focus some tribal and community spiritual support to help students succeed in college. Aligning traditional spiritual practices and college success would also minimize the perceived conflict between college success and maintaining cultural identity (cf. Benally, 1994).

At the institutional level, we suggest that the advisement dialogue, both prior to college and at college, be expanded to include discussions of loneliness, negative peer pressure, and the risks of acculturation and bicultural identity-especially racism. This dialogue might take place in several contexts. One professional context would be the high school counseling office, which could facilitate the discussion among students and their peers, between parents and students, and between tribal leaders and students. Another professional context would be the multicultural office or Native American student support organization. These entities might also facilitate dialogue among 
Native American students about the acculturative process of being in college and its risks and benefits.

The prevalence of experiences of racism among our participants was discouraging. Their descriptions of these instances were typically the most painful and poignant aspects of the interviews. Our surprise at their prevalence reminded us of our own denial and wishful thinking about racial issues. We suspect that we are not alone. As European American faculty at predominantly European American universities, we suspect that our overly optimistic attitudes are representative of the racism of denial that still prevails on college campuses. On a related note, we were discouraged to see that so little research had been done to explore racially oppressive experiences among Native American students. We see this as additional evidence of institutionalized racism against Native American students. It appears to us that Native American students are the minority among minorities, and as such may still be subject to prejudices that more populous minorities have begun to overcome. Additional research is needed to understand these issues. Likewise, our study highlights the importance of maintaining efforts at achieving cross-cultural competence among students, faculty, and administrators alike.

Over the course of the interviews and their analysis, we were persuaded that Native American support programs are very important in helping students transition to and survive in the university setting. Accordingly, we recommend that proactive, mandatory programs might be the most efficient and effective means of helping students. We realize that this recommendation might sound offensive because it seems to restrict autonomy. It sounded that way to us when we heard our participants suggest it; however, autonomy, at the individual level, is a European American value, not a value of most Native American cultures (Jackson \& Turner, in press). Many students who grow up on reservations have experienced a more collectivist approach to education and development, and may be discouraged by the individualistic and autonomous value base of the typical college campus. A nurturing, collectivist island in this sea of individualism seems important - perhaps more important than whether students happen to be autonomous enough to find it on their own.

Structured mentoring programs that connect advanced Native American students with beginning students may be another means of addressing the potential isolation of Native American students on campuses. Such programs would address two of the barriers identified in our study. First, the potentially negative influences of friends would be mitigated by having a mentor who was clearly supportive of academic success. Second, a mentor could serve as a model for reconciling the conflicting pressures inherent in developing a bicultural identity. Though our participants did not specifically mention mentors as important influences in their success, we inferred from their descriptions of the social support they received from multicultural offices and Native American programs that they were able to connect with informal mentors through these groups. We suggest that formalizing this process, perhaps as a function of the social support groups, would help students who have difficulty making those connections themselves.

Similarly, our experience with our participants suggests the benefits of having a personal relationship with a faculty member or staff person at the university. We 
suggest that concerted, proactive efforts to establish such relationships early in the students' college experience would increase the likelihood of retention. On a personal note, we as researchers were deeply touched by the openness of the participants. The participants had no reason to volunteer to be in the study or to be cooperative and frank in the interviews. We were sensitive to the implied power differential in our interviews and were uncertain about how open the participants would be. It was encouraging to find that we experienced a surprising level of connection with the participants despite our relatively brief interaction with them. Certainly faculty and staff members could develop significantly deeper and more meaningful relationships with the Native American students on their campuses given their opportunities for prolonged contact and dialogue.

Correspondence concerning this article should be addressed to Aaron P. Jackson, 340-J MCKB, Brigham Young University, Provo, UT 84602; aaron_jackson@byu.edu

\section{APPENDIX.}

\section{Interview Guidelines and Sample Questions}

The interviews will be conducted using an unstructured format. The following questions are typical of those that will be asked in the course of the interview. Reflective listening and minimal encouragers will be used to maximize participant responses and increase the depth of interview content. In each area, efforts will be made to help participants address areas of likely relevance to success in college (e.g., family, faculty, finances, relationships, friends, spiritual issues, academic programs, student programs, etc.). The actual wording of the questions will be adapted to be appropriate to context and the flow of the interview.

1. Please describe your experience here at (college name).

2. Can you tell us about your experience before coming to college that seemed to make a difference while you've been a student here?

3. What kinds of things have been most helpful to you while in school here?

4. What kinds of things have made school more difficult?

5. How have your family members been involved in your education?

6. How have your friends been involved in your education?

7. What advice would you give to someone who was coming to college from circumstances similar to yours when you came to college?

8. If you were to design a college, what would you do differently to help students like yourself?

9. What are your plans as you graduate? 


\section{REFERENCES}

Benally, J. H. (1994). Navajo philosophy of learning and pedagogy. Journal of Navajo Education, 12(1), 23-31.

Benjamin, D. P., Chambers, S., \& Reiterman, G. (1993). A focus on American Indian college persistence. Journal of American Indian Education, 32, 24-40.

Braithwaite, C. A. (1997, November/December). Helping students from tribal colleges succeed. About Campus, 2, 19-23.

Brown, L. L., \& Kurpius, S. E. R. (1997). Psychosocial factors influencing academic persistence of American Indian college students. Journal of College Student Development, 38, 3-12.

Denzin, N. K., \& Lincoln, Y. S. (2000). The discipline and practice of qualitative research. In N. K. Denzin \& Y. S. Lincoln (Eds.), Handbook of qualitative research (2nd ed., pp. 1-29). Thousand Oaks, CA: Sage.

Herring, R. D. (1999). Counseling with Native Americans and Alaska Natives. Thousand Oaks, CA: Sage.

Hoover, J. J., \& Jacobs, C. C. (1992). A survey of American Indian college students: Perceptions toward their study skills/college life. Journal of American Indian Education, 32, 21-29.

Hornett, D. (1989). The role of faculty in cultural awareness and retention of American Indian college students. Journal of American Indian Education, 29, 12-19.

Hoshmand, L. T. (1989). Alternate research paradigms: A review and teaching proposal. The Counseling Psychologist, 17, 3-79.

Huffman, T. E. (1991). The experiences, perceptions, and consequences of campus racism among Northern Plains Indians. Journal of American Indian Education, January, 25-34.

Jackson, A. P., \& Patton, M. J. (1992). A hermeneutic approach to the study of values in counseling, Counseling and Values, 36, 201-209.

Jackson, A. P., Slife, B. D., \& Williams, D. C. (2003). Relationism: A non-lethal philosophy for counseling psychology. Manuscript submitted for publication. Brigham Young University.

Jackson, A. P., \& Smith, S. A. (2001). Postsecondary transitions among Navajo Indians. Journal of American Indian Education, 40(2), 28-47.

Jackson, A. P., \& Turner, S. (in press). Counseling and psychotherapy with Native Americans. In T. Smith \& S. Richards (Eds.), Practicing multiculturalism. Boston: Allyn \& Bacon.

Kerbo, H. R. (1981). College achievement among Native Americans: A research note. Social Forces, 59, 1275-1280.

Kvale, S. (1987). Validity in the qualitative research interview. Methods, 1, 37-72.

Kvale, S. (1996). Interviewing: An introduction to qualitative research interviewing. Thousand Oaks, CA: Sage.

LaFromboise, T. D., \& Low, K. G. (1989). American Indian children and adolescents. InJ. T. Gibbs \& L. N. Huang (Eds.), Children of color (pp. 114-147). San Francisco: Jossey-Bass.
Lamborn, S., Solberg, V. S., Torres, J., Gusavac, N., Hamman, T., Pogoriler, D., et al. (1997, August). The role of family and ethnicity factors on college outcomes. Paper presented at the annual meeting of the American Psychological Association. Chicago.

Lee, T. W., Mitchell, T. R., \& Sablynski, C. J. (1999). Qualitative research in organizational and vocational psychology, Journal of Vocational Behavior, 55, 161-187.

Lin, R. L. (1990). Perception of family background and personal characteristics among Indian college students. Journal of American Indian Education, 29, 19-26.

Lin, R., LaCounte, D., \& Eder, J. (1988). A study of Native American students in a predominantly White college. Journal of American Indian Education, 27, 8-15.

Martin, W. E., Jr. (1991). Career development and American Indians living on reservations: Cross-cultural factors to consider. Career Development Quarterly, 39, 273-283.

McCormick, R. M., \& Amundson, N. E. (1997). A careerlife planning model for First Nations people. Journal of Employment Counseling, 34, 171-179.

McInerney, D. M., \& Swisher, K. G. (1995, Spring). Exploring Navajo motivation in school settings.Journal of American Indian Education, pp. 28-51.

Ness, J. K. E. (2001). American Indian completers and noncompleters in a tribal and community college in Northern Minnesota. Unpublished doctoral dissertation, University of Minnesota.

Packer, M. J. (1985). Hermeneutic inquiry in the study of human conduct. American Psychologist, 40, 1081-1093.

Patton, M. Q. (1990). Qualitative evaluation and research methods (2nd ed.). Newbury Park, CA: Sage.

Polkinghorne, D. E. (1984). Further extensions of methodological diversity for counseling psychology. Journal of Counseling Psychology, 31, 416-429.

Polkinghorne, D. E. (1991). Generalization and qualitative research: Issues of external validity. Paper presented at the American Educational Research Association Annual Meeting, Chicago.

Reddy, M. A. (Ed.). (1993). Statistical record of native North Americans. Washington, DC: Gale Research.

Rindone, P. (1988). Achievement motivation and academic achievement of Native American students. Journal of American Indian Education, 28, 1-7.

Sakiestewa, G. W. (1996). Bridging the gap between high school and college: A successful program that promotes academic success for Hopi and Navajo students. Paper presented at Retention in Education for Today's American Indian Nations. Tucson, AZ.

Sanders, D. (1987). Cultural conflicts: An important factor in the academic failures of American Indian students. Journal of multicultural counseling and development, 15, pp. $81-90$

Schwandt, T. A. (2000). Three epistemological stances for qualitative inquiry. In N. K. Denzin \& Y. S. Lincoln (Eds.), Handbook of qualitative research, 2 nd ed. (pp. 189-213). Thousand Oaks, CA: Sage. 
Steward, R. J. (1993). Two faces of academic success: Case studies of American Indians on a predominantly Anglo university Campus. Journal of College Student Development, 34, 191-196.

Sydell, E. J., \& Nelson, E. S. (2000). Modern racism on campus: A survey of attitudes and perceptions. The Social Science Journal, 37(4), 627-635.

U.S. Department of Education. (1998). American Indians and Alaska Natives in Postsecondary Education. Washington, DC: U.S. Government Printing Office.
Ward, C. (1998). Community resources and school performance: The Northern Cheyenne case. Sociological Inquiry, 68(1), pp. 83-113.

West, D. K. (1988). Comparisons of career maturity and its relationship with academic performance. Journal of American Indian Education, 27, 1-7.

Willeto, A. A. A. (1999). Navajo culture and family influences on academic success: Traditionalism is not a significant predictor of achievement among young Navajos. Journal of American Indian Education, 38(2), pp. 1-24. 